РЕГИОНОВЕДЕНИЕ

DOI: 10.17805/ggz.2018.1.5

\title{
Китайский юань: \\ дорога в тысячу ли начинается с первого шага
}

А. В. Шотина

Московский гуманитарный университет

Статья посвящена появлению китайского юаня в корзине специальных прав заимствования Международного валютного фонда. В работе отражены причины включения юаня в корзину СПЗ МВФ, а также последствия, которые могут иметь место в будущем.

Ключевые слова: китайский народный юань; специальные права заимствования; мировая резервная валюта; Международный валютный фонд; доллар США; международные резервы; золотовалютные резервы

\section{Chinese Yuan:}

\section{A Journey of a Thousand Li Begins with One First Step}

A. V. Shotina

Moscow University for the Humanities

The article deals with the inclusion of Chinese yuan into the Special Drawing Rights basket of the International Monetary Fund. The author determines the causes of adding yuan to the SDR basket as well as the consequences that may take place in the future.

Keywords: Chinese people's yuan; special drawing rights; world reserve currency; International Monetary Fund; U.S. dollar; international reserves; gold and currency reserves

В последнее время оживились разговоры вокруг темы мировых резервных валют. И это неспроста. 1 октября 2016 г. китайский юань был официально включен в список мировых резервных валют. Однако следует обратить внимание на то, что роль китайской валюты на данный момент ограничена участием в специальных правах заимствования (CПЗ) или SDR (англ. - Special Drawing Rights). Ни для кого не секрет, что Китай занимает второе место в мире по объему ВВП после США. Из этого следует, что и значимость китайской народной валюты будет неуклонно расти.

Новизна данной темы исследования заключается в том, что именно сейчас, на наших глазах, происходят исторические изменения в междуна- 
родной валютной системе. Включение китайского юаня в корзину СПЗ прямое тому доказательство. Больше 30 лет состав корзины СПЗ не менялся. Стоит отметить, что юань действительно становится все более и более востребованным центральными банками различных стран. Все больше и больше торговых операций проводятся именно в юанях.

При написании настоящей работы были взяты за основу научные статьи и рассуждения Хань Чао, Д. Н. Колесова, Ю. А. Назаровой, Н. В. Хованова, В. Ю. Катасонова, О. Ю. Рявкиной и других. В своих работах (Хань Чао, 2017: Электронный ресурс; Колесов, Назарова, Хованов, 2016; Катасонов, 2016; Рявкина, 2016) эксперты уделяют особое внимание причинам включения китайского юаня в список мировых резервных валют и перспективам того, насколько юань будет конкурентоспособен с другими валютами, прежде всего, с долларом США.

Что же такое резервная валюта? Резервная валюта — это признанная мировая валюта, которая накапливается центральными банками стран с целью пополнения своих золотовалютных резервов и укрепления национальной валюты. Главным свойством, которым должна обладать резервная валюта - это ее устойчивость (Актуальные ... : Электронный ресурс; Мировые резервные валюты: Электронный ресурс; Мировые резервные ... , 2016: Электронный ресурс; Резервная валюта: Электронный ресурс; Резервная валюта ... : Электронный ресурс; Что такое мировые резервные валюты ... , 2017: Электронный ресурс). Ни одно государство не рискнет держать финансовые запасы в нестабильной валюте, подверженной влиянию внешних факторов. Каждая страна сама имеет полное право выбрать денежную единицу, в которой предпочтет хранить свои валютные резервы. Международные финансовые организации или другие государства не вправе устанавливать это в принудительном порядке (Значимость мировых резервных валют, 2017: Электронный ресурс). Немаловажно отметить, что большинство стран предпочитает держать валютные сбережения в нескольких резервных валютах сразу. Данный способ хранения средств гарантирует большую стабильность и защищенность от непредвиденных обстоятельств на мировом финансовом рынке.

Включение в корзину СПЗ китайского юаня ознаменовало собой первое изменение в составе валют с 1980 г. (МВФ включает китайский юань ... , 2016: Электронный ресурс; Седлов, 2018: Электронный ресурс; Юань включен ... , 2018: Электронный ресурс). Ранее число резервных валют равнялось 16, однако с 1999 г. евро пришел на замену сразу двум валютам немецкой марке и французскому франку. На сегодняшний день полноправными резервными валютами принято считать доллар США, евро, английский фунт стерлингов, японскую йену и швейцарский франк. Однако поми- 
мо вышеперечисленной пятерки существует корзина специальных прав заимствования. СПЗ - безналичное платежное средство Международного валютного фонда, созданное в 1969 г. Это международный резервный актив, используемый для пополнения официальных резервов членов МВФ. На данный момент корзина СПЗ включает в себя пять мировых валют: доллар США, евро, японскую йену, английский фунт стерлингов и, наконец, китайский юань. В корзине СПЗ по процентному соотношению юань занимает достойную третью позицию.

В 2015 г. МВФ принял новую формулу для расчета весов валют в корзине СПЗ, которая заменила старую, действовавшую с 1978 г. Согласно принятой формуле, доли для экспорта валюты эмитента и свободного финансового показателя равны. Как отмечает Хань Чао, «этот финансовый индикатор в равных долях включает официальные резервы, которые выражены в валюте государства-члена Фонда (или валютного союза) и которые хранятся другими органами денежно-кредитного регулирования, не являющимися эмитентами данной валюты, оборот валютного рынка в данной валюте, а также сумму непогашенных международных банковских обязательств и международных долговых ценных бумаг, выраженных в этой валюте. Критерий экспорта, служащий в качестве допуска, призван обеспечивать выпуск валют, которые могут включаться в корзину, государствамичленами или валютными союзами, имеющими ведущую роль в мировой экономике» (Хань Чао, 2017: Электронный ресурс).

Так кто же решает, какую валюту повысить до статуса мировой резервной валюты? Ответ прост - Международный валютный фонд. МВФ является крупнейшей мировой кредитной организацией. Именно она оценивает состояние экономик стран и их золотовалютных резервов. Двумя главными критериями МВФ, необходимыми для включения валюты в корзину мировых резервных валют, являются масштабы и развитость экономики.

На первый взгляд, может показаться, что эти два понятия абсолютные синонимы, но это не так. К примеру, в XVIII-XIX вв. самой развитой экономикой в мире была экономика Великобритании. Соответственно, главной мировой валютой являлся английский фунт стерлингов. Хотя самая масштабная экономика была в США, но на тот момент доллар не признавался в качестве доминирующей мировой валюты (Белый, 2016: Электронный ресурс).

То же самое сейчас происходит и с Китаем. По мнению многих экспертов, вскоре КНР может выйти на первое место как крупнейшая экономика в мире (10 самых крупных ... , 2017: Электронный ресурс; Тройхо, 2017: Электронный ресурс). Однако с точки зрения развитости экономика Китая до сих пор отстает от ряда стран по многим показателям. Например, по до- 
ходу ВВП на душу населения в 2017 г. Китай занял лишь 75 строчку мирового рейтинга. Еще одной из тормозящих причин выступает проблема экологии. Плохое качество воздуха, питьевых ресурсов и продуктов негативно сказывается на здоровье населения, что вызывает критику со стороны Международной организации здравоохранения.

Почему же вопреки этим нюансам в качестве новой резервной валюты СПЗ МВФ выбрал китайский народный юань? Стоит уделить особое внимание рассмотрению причин включения юаня в корзину СПЗ.

Первая причина неразрывно связана с увеличившимся использованием юаня. С тех пор как в 2010 г. состоялся пересмотр корзины СПЗ, доля юаня в международных платежах заметно выросла. Активность операций с юанями на валютных рынках также существенно возросла, что позволяет уже сейчас реализовывать сделки в масштабах, присущих деятельности МВФ. Именно этот фактор стал доказательством широкого использования китайского юаня на международном рынке.

Второй причиной стали операционные аспекты. В настоящее время финансовые операции без особых препятствий можно проводить в юанях, что является прямым результатом недавних финансовых реформ китайских властей. Вышеупомянутые реформы представляют собой решения о предоставлении официальных резервов управляющим и их агентам и полный доступ к инструментам с фиксированным доходом на национальном и валютном рынках. Также реформы коснулись программы содействия международному использованию китайского юаня и укрепления макрофинансовой стабильности. Данная программа включает в себя полную либерализацию внутренних процентных ставок, создание новой трансграничной межбанковской системы платежей, а также шаги по направлению к обменному курсу. Чаще всего обменный курс определяется именно рыночными факторами. Стоит заметить, что операционные вопросы не входят в список официальных требований для включения в корзину СПЗ. Поэтому вторую причину можно рассматривать как дополнительный плюс китайскому юаню.

Третья, но немаловажная причина - это дополнительные меры по улучшению раскрытия данных. Опять же, этот фактор не включен в число формальных критериев оценки валюты в качестве резервной валюты СПЗ, так как эмитенты этих валют отвечают высоким стандартам прозрачности.

С включением китайского юаня выросла и привлекательность корзины СПЗ в качестве международного резервного актива. Корзина валют СПЗ стала более диверсифицированной. Теперь китайская валюта официально включена в расчет процентной ставки по СПЗ, что повлекло за собой изменения в обмене валют между МВФ и Китаем. Благодаря этому будущие операции МВФ будут осуществляться в юанях. Очень важно отметить, что 
официальные органы, отвечающие за все валюты корзины СПЗ, должны продолжать неуклонно следовать принципам экономической политики. Основы экономической политики способствуют операциям МВФ, его государств-членов и других стран с резервными валютами СПЗ.

Появление китайского юаня в корзине СПЗ свидетельствует об интернационализации национальной валюты Китая. За последние годы власти КНР существенно ослабили контроль над движением капитала, тем самым позволив использовать свою национальную валюту в зарубежных банках. Китайский юань не привязан к доллару США, и поэтому его колебания практически незаметны. Китайские власти активно предоставляют юань другим государствам посредством свопов между центральными банками. Первой из развитых стран, которая выпустила облигации, номинированные в юанях, стала Великобритания в 2014 г. Вслед за этим Банк России 27 ноября 2015 г. официально включил китайский народный юань в список валют для инвестиций золотовалютных резервов.

15 января 2018 г. стало известно, что центральные банки Германии и Франции приняли решение о внесении юаня в международные резервы (Бундесбанк включил ... , 2018: Электронный ресурс). В этот день на Азиатском финансовом форуме в Гонконге Андреас Домбре, член управляющего совета Бундесбанка, заявил о решении включить китайский юань в валютные резервы. По словам представителя Бундесбанка, решение было принято еще в середине 2017 г. (Black, Engle, Curran, 2018: Электронный ресурс). Немецкие власти последовали примеру вложения инвестиций Евроцентробанком в размере $€ 500$ млн в юаневые активы. Центральный банк Франции в своем заявлении также отметил, что юань состоит в числе «ограниченных валют», в которых содержится часть их валютных резервов. Однако наибольшая доля золотовалютных резервов представлена в долларах США. Как объясняют Центробанки Германии и Франции, хранение части валютных резервов в китайских юанях связано с диверсификацией (ЦБ ФРГ и Франции сообщили ... , 2018: Электронный ресурс). Банки Бельгии и Словакии также инвестировали долю средств в юань. Правительство Испании заявило, что планирует поступить таким же образом (ЦБ Европы увеличивают долю юаня ..., , 2018: Электронный ресурс).

Еще одним ключевым событием в финансовом мире, имевшим место ранее, стало создание Центробанком КНР Китайской международной платежной системы (англ. China International Payments System, CIPS). Первая фаза была запущена 8 октября 2015 г. в Шанхае. Главная функция системы - обработка трансграничных сделок в юанях. Благодаря созданию CIPS было ликвидировано последнее препятствие для международного использования китайской национальной валюты. Таким образом, в настоящее время 
юань является широко используемой валютой. Однако его использование на глобальном рынке пока несравнимо с масштабами вовлеченности Китая в мировую торговлю.

В статьях соглашения МВФ термин «свободно используемая валюта» определяется как валюта, широко используемая для платежей по международным операциям, а также представляющая собой предмет активной торговли на ключевых валютных рынках.

Исполнительный совет МВФ выделяет несколько показателей, служащих для оценки свободного использования валют: доли валют в объемах резервов и валютное выражение международных долговых ценных бумаг, а также международных банковских обязательств — в качестве индикаторов для оценки широты использования валюты, а оборот операций на валютных рынках — для оценки, насколько широко проводятся операции с валютой. Существуют дополнительные факторы оценки свободного использования валют. К данным критериям относятся: официальные резервы в виде активов в иностранной валюте, выпуск международных долговых ценных бумаг, трансграничные платежи и финансирование торговли (Хань Чао, 2017: Электронный ресурс).

Включение китайского народного юаня в корзину резервных валют СПЗ не гарантирует его немедленного использования как резервной валюты. Здесь, скорее всего, можно говорить больше о значимости получения такого статуса. Крупнейшая финансовая организация признала юань как одну из самых надежных и стабильных валют в мире, что существенно повышает интерес инвесторов. Хотя для прямых инвестиций КНР уже давно выступает главной страной-реципиентом. Как будут обстоять дела с портфельными инвестициями, уже будет зависеть от готовности Китая идти по пути большей либерализации движения капиталов.

Статус резервной валюты СПЗ влечет за собой не только привилегии, но и обязательства. По требованиям МВФ китайские власти должны детально раскрыть состав своих золотовалютных резервов, иными словами, сделать их более транспарентными.

Немаловажным условием для любой валюты, претендующей на звание полноправной резервной валюты, является ее конвертируемость. Китайский юань представляет собой частично конвертируемую валюту. Народный банк Китая, по мнению международных экспертов, искусственно занижает курс юаня на 30-40\%, что существенно повышает конкурентоспособность китайской продукции. Большинство развитых стран, особенно США, выступают с требованием по отношению к правительству КНР сделать юань свободно конвертируемой валютой. Однако Китай не спешит прибегать к таким радикальным финансовым реформам и продолжает контролировать 
курс народного юаня. До тех пор, пока китайское правительство не примет решение превратить юань в полностью конвертируемую валюту с плавающим курсом, речи о статусе полноценной мировой резервной валюты быть не может. Соответственно, о серьезной конкуренции юаня и доллара США еще рано говорить.

Включение юаня в корзину СПЗ можно рассматривать как важную веху в процессе интеграции КНР в глобальную финансовую систему. Это событие, которого так давно ждали китайские власти, стало ярким доказательством мирового признания успехов экономических реформ. Тем самым, долгий путь китайского юаня к статусу резервной валюты может послужить очень хорошим примером валютной политики государства, способной, в конечном итоге, привести свою национальную валюту до высокого уровня международного признания.

По мере дальнейшего углубления интеграции экономики Китая в мировую финансовую систему и схожих процессов в других государствах с формирующимся рынком, все это может повлечь за собой создание новой международной валютной системы, которая сможет обеспечить еще больший рост мировой экономики и стабильность на мировом финансовом рынке.

\section{СПИСОК ЛИТЕРАТУРЫ}

Актуальные сегодня резервные валюты, их понятие и значимость [Электронный ресурс] // Биржевой навигатор. URL: http://stock-list.ru/reserve-currencies.html [архивировано в WaybackMachine] (дата обращения: 11. 01.2018).

Белый, К. (2016) Мировые резервные валюты [Электронный ресурс] // Финансовый гений. 6 марта. URL: http://fingeniy.com/mirovye-rezervnye-valyuty/ [архивировано в WaybackMachine] (дата обращения: 10.01.2018).

Бундесбанк включил юань в валютные резервы. (2018) [Электронный pecypc] // Finanz.ru. 15 января. URL: http://finanz.ru/novosti/valyuty/bundesbank-vklyuchil-yuan-v-valyutnye-rezervy-1013087422 [архивировано в WaybackMachine] (дата обращения: 16.01.2018).

Значимость мировых резервных валют (2017) [Электронный ресурс] // Деньги.Форекс. 29 мая. URL: https://dengifx.com/finansovaya-gramotnost/mirovye-rezervnye-valyuty [архивировано в WaybackMachine] (дата обращения: 11.01.2018).

Катасонов, В. Ю. (2016) МВФ и юань // Международная экономика. № 1. С. 53-55.

Колесов, Д. Н., Назарова, Ю. А., Хованов, Н. В. (2016) Модель оценки покупательной способности китайского юаня при помощи стабильных «корзин» резервных валют МВФ // Устойчивое развитие: общество и экономика : материалы III Международной научно-практической конференции 
«Устойчивое развитие: общество и экономика», Санкт-Петербург, 20-23 апреля 2016 г. СПб. : Санкт-Петербург. гос. ун-т. 683 с. С. 584-585.

МВФ включает китайский юань в корзину специальных прав заимствования (2016) [Электронный ресурс] // Международный валютный фонд. 30 сентября. URL: https://imf.org/ru/News/Articles/2016/09/29/AM16-NA0930 16IMF-Adds-Chinese-Renminbi-to-Special-Drawing-Rights-Basket [архивировано в WaybackMachine] (дата обращения: 10.01.2018).

Мировые резервные валюты [Электронный ресурс] // База Форекс трейдера. URL: http://forex-traider.ru/foreks-stati/1638-mirovye-rezervnye-valjuty [архивировано в WaybackMachine] (дата обращения: 12.01.2018).

Мировые резервные валюты: понятие и основные функции (2016) [Электронный ресурс] // Курсы валют в банках Москвы. 6 апреля. URL: https://exocur.ru/mirovyie-rezervnyie-valyutyi-ponyatie-i-osnovnyie-funktsii/ [архивировано в WaybackMachine] (дата обращения: 13.01.2018).

Резервная валюта (reserve currency) [Электронный ресурс] // Определения экономических терминов. URL: http://economic-definition.com/Currencies/Rezervnaya_valyuta_reserve_currency_eto.html [архивировано в WaybackMachine] (дата обращения: 10.01.2018).

Резервная валюта [Электронный ресурс] // Forex Club. URL: https://fxclub.org/rezervnaya-valyuta/ [архивировано в WaybackMachine] (дата обращения: 10.01.2018).

Рявкина, О. Ю. (2016) Перспективы юаня как резервной валюты МВФ // Культура - Искусство - Образование : XXXVII науч.-практич. конференция профессорско-преподавательского состава вуза / сост., авт. предисл. А. В. Штолер. Челябинск : Челябинск. гос. ин-т культуры. 376 с. С. 63-66.

Седлов, Д. (2018) Китайский доллар. Сможет ли юань стать настоящей резервной валютой [Электронный ресурс] // Forbes. 17 января. URL: http://forbes.ru/finansy-i-investicii/355795-kitayskiy-dollar-smozhet-li-yuan-statnastoyashchey-rezervnoy-valyutoy [архивировано в WaybackMachine] (дата обращения: 18.01.2018).

Тройхо, М. (2017) 2017 - год утверждения Китая в роли сверхдержавы [Электронный pecypc] // ИноСМИ.ru. 23 декабря. URL: https://inosmi.ru/politic/20171223/241076983.html [архивировано в WaybackMachine] (дата обращения: 11.01.2018).

Хань Чао. (2017) Соответствие китайского юаня требованиям МВФ для включения в корзину СДР [Электронный ресурс] // Научное обозрение. Международный науч.-практич. журнал. № 1. URL: https://srjournal.ru/ 2017/id34/ [архивировано в WaybackMachine] (дата обращения: 14.01. 2018).

ЦБ Европы увеличивают долю юаня в валютных резервах (2018) [Электронный ресурс] // Вести. Экономика. 16 января. URL: http://vestifinance.ru/articles/96376 [архивировано в WaybackMachine] (дата обращения: 16.01.2018). 
ЦБ ФРГ и Франции сообщили о хранении ЗВР в юанях (2018) [Электронный ресурс] // Рамблер. 16 января. URL: https://news.rambler.ru/economics/38892795-tsb-frg-i-frantsii-soobschili-o-hranenii-zvr-v-yuanyah/ [архивировано в WaybackMachine] (дата обращения: 16.01.2018).

Что такое мировые резервные валюты, какие они бывают, и с чем их едят (2017) [Электронный ресурс] // Капиталист. 2 февраля. URL: http://capitalgains.ru/stati/mirovye-rezervnye-valyuty.html [архивировано в WaybackMachine] (дата обращения: 14.01.2018).

Юань включен в международные резервы Бундесбанка (2018) [Электронный ресурс] // Росбалт. 15 января. URL: http://rosbalt.ru/business/2018/ 01/15/1674426.html [архивировано в WaybackMachine] (дата обращения: 16.01.2018).

10 самых крупных мировых экономик в 2017 году (2017) [Электронный ресурс] // Business Views. 2 мая. URL: http://businessviews.com.ua/ru/ economy/id/krupnejshie-ekonomiki-mira-1540/ [архивировано в WaybackMachine] (дата обращения: 13.01.2018).

Black, J., Engle, S., Curran, E. (2018) Bundesbank says it'll add China's yuan to currency reserves [Электронный pecypc] // Bloomberg. January 14. URL: https://bloomberg.com/news/articles/2018-01-15/bundesbank-to-includeyuan-in-currency-reserves-dombret-says [архивировано в WaybackMachine] (дата обращения: 17.01.2018).

Дата поступления: 20.02.2018 г.

Шотина Анна Владимировна - магистрант факультета международных отношений и туризма Московского гуманитарного университета. Адрес: 111395, Россия, г. Москва, ул. Юности, 5. Тел.: +7 (499) 374-55-81. Эл. адрес: AniaSunLeo@yandex.ru. Научный руководитель - кандидат юридических наук, доцент кафедры истории и регионоведения факультета международных отношений и туризма Московского гуманитарного университета Вячеслав Иванович Балакин.

Shotina Anna Vladimirovna, Master's Degree Student, Faculty of International Relations and Tourism, Moscow University for the Humanities. Postal address: 5 Yunosti St., 111395 Moscow, Russian Federation. Tel.: +7 (499) 374-5581. E-mail: AniaSunLeo@yandex.ru. Academic adviser: Vyacheslav Ivanovich Balakin, Candidate of Law, Associate Professor, Department of History and Regional Studies, Faculty of International Relations and Tourism, Moscow University for the Humanities.

Для циитирования:

Шотина А. В. Китайский юань: дорога в тысячу ли начинается с первого шага [Электронный ресурс] // Горизонты гуманитарного знания. 2018. № 1. C. 82-90. URL: http://journals.mosgu.ru/ggz/article/view/703 (дата обращения: дд.мм.гггг). DOI: 10.17805/ggz.2018.1.5 